JOURNAL OF THE SOUTH AFRICAN INSTITUTION OF CIVIL ENGINEERING

ISSN 1021-2019

Vol 62 No 1, March 2020, Pages 10-21, Paper 0723

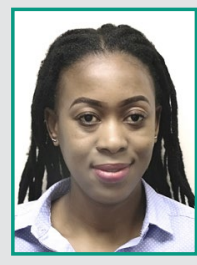

MAPHOLEE LOKE is a Candidate Engineering Technologist and a SAICE student member. She obtained a Diploma in Civil Engineering at Lerotholi Polytechnic (Lesotho) in 2014, a BTech from the Cape Peninsula University of Technology in 2016, and is currently pursuing a Master's degree in Civil Engineering, working on heritage buildings. She worked as a geotechnical laboratory technician, water and sanitation technician, construction supervisor and quantity surveyor for the Lesotho Lowlands Bulk Water Supply Scheme.

Contact details:

Department of Civil Engineering and Surveying

Cape Peninsula University of Technology

P0 Box 1906, Bellville 7535, South Africa

$\mathrm{T}:+27761289616$

E:lokemaphole@gmail.com

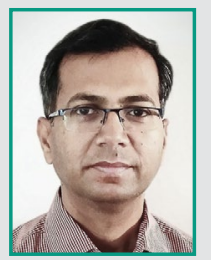

DR KUMAR PALLAV, who has 16 years of academic and research experience in the area of structural engineering, received his PhD degree from IIT Guwahati, India. After completing his Master's, he started teaching at Government College Ujjain, India, in 2003. He was Erasmus Academic Fellow at the Universitat de Politechnica de Catalunya,

Barcelona, in 2010 and 2011, and at the (zech Technical University, Prague. He has supervised and examined doctoral and postgraduate dissertations. His research interests are in the areas of heritage/old structures, structural dynamics and earthquake hazards. He also serves as a reviewer for reputed journals and as committee member of international conferences.

\section{Contact details:}

Department of Civil Engineering and Surveying

Cape Peninsula University of Technology

PO Box 1906, Bellville 7535, South Africa

$\mathrm{T}:+27219598762$

E: kumarp@cput.ac.za

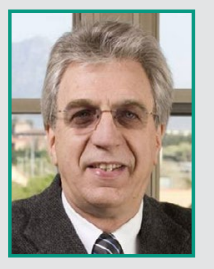

PROF RAINER HALDENWANG received his NHD, MDipl and DTech (Civil Engineering) from the Cape Peninsula University of Technology. After graduating, he spent ten years in harbour engineering at Saldanha Bay, working for Portnet. In 1978 he joined the then Cape Technikon as a lecturer. From 2008, as Associate Professor in the

Department of Civil Engineering, he was responsible for the final-year research projects, supervised postgraduate students and headed a research group investigating the flow behaviour of non-Newtonian fluids in pipes, flumes, fittings and pumps, as well as self-compacting concrete. He retired in 2018, but still supervises post-graduate students.

\section{Contact details:}

Department of Civil Engineering and Surveying

Cape Peninsula University of Technology

PO Box 652, Cape Town 8000, South Africa

T: +27214603512

E: haldenwangr@cput.ac.za

\title{
Characterisation of heritage cementing materials for restoration purposes: A review
}

\author{
M E Loke, Kumar Pallav, R Haldenwang
}

Characterisation of heritage cementing materials has become a topic of great importance in the protection of culture and history for future generations. The original cementing material analysis helps to achieve compatible and long-term restoration of heritage buildings. The analysis is done for different purposes - research, compatibility assessment prior to restoration and/or documentation. There are several analytical techniques that many researchers use for analysing the composition of original cementing materials. However, until the present time, the choice of the analytical method depended solely on the researchers' discretion and personal preference. The common methods include microscopic, wet chemical and x-ray analyses. The purpose of this paper is to review the technical literature pertaining to the characterisation (physical, chemical, mineralogical and mechanical) of original heritage cementing materials and its application in proposed restoration work. The knowledge of originally used materials and types of binder, aggregates and additives (in some cases) is considered a useful tool in the search of the compatible repair materials by the construction industry, especially in South Africa where the standard procedure for heritage cementing material characterisation has not been well documented.

\section{INTRODUCTION}

Heritage buildings are structures with proven exceptional and significant qualities that represent the country's aesthetic culture and military history, politics or special events of the past. All countries around the world have these historical legacies that tell a unique story about their history. Heritage structures serve as true historical symbols and a resemblance of unique ancient architecture and culture (Gleize et al 2009; Sandbhor \& Botre 2013; Hormes et al 2016). The selection of world heritage structures is based on their outstanding universal values, hence they are protected by the United Nations Educational, Scientific and Cultural Organisation (UNESCO). Examples of heritage structures around the world include the Colosseum in Rome, the Old Jerusalem City and its Walls, the Leaning Tower of Pisa in Italy, and St Mary's Cathedral and St Michael's Church at Hildesheim in Germany. In South Africa, heritage sites were protected by the National Monuments until recently when the Department of Arts and Culture (under the National Heritage Resources Act, No 25 of 1999) tasked the South African Heritage Resources Agency (SAHRA) with the identification and management of such sites. These sites include Robben Island, the South African Astronomical Observatory (SAAO) and the
Castle of Good Hope (World Heritage Sites in South Africa 2018; SAHRA 2018c).

Looking at these structures today, centuries later, they are a reminder of a rich, distinguished and prosperous past - confirmation of the culture, history and accomplishments of their countries since their construction. Meli et al (2007) stated that historical buildings tend to last longer compared to most modern structures which show signs of defects after a few years. These special structures attract tourists to a country leading to economic growth. The travel and tourism industry has contributed greatly towards global Gross Domestic Product (GDP) and employment. For example, the South African figures in 2017 are: $2.9 \%$ direct and $8.9 \%$ total contribution to GDP, while the direct and total contributions to employment are $4.5 \%$ and $9.5 \%$ respectively (World Travel and Tourism Council 2018).

Nonetheless, due to ageing, and various factors such as chemical and biological processes, historical structures deteriorate with very visible signs of material failure. Some of the major factors include neglect and ignorance by humans. Additional factors are of a climatic and environmental nature, such as high humidity, high rainfall, temperature changes due to seasonal changes and drastic fluctuations in day and night temperatures, 
atmospheric moisture, exposure to soluble salts, air pollution, and biological attack by plants and animals (Lawrence et al 2004). If these heritage legacies are not properly restored, the economy suffers because of repeated repairs and loss of authenticity during restoration, resulting in a reduction in tourist attraction. It is therefore essential to ensure their continued existence and functionality, which are largely dependent on proper maintenance and repair. Characterisation of the originally used cementing materials in heritage structures ensures proper restoration with materials that have similar properties, or at least as close to the original material as possible (Arıoglu \& Acun 2006; Historic England 2018a). As mentioned by Salvadori (1982) and Holmes and Wingate (1997), mortar plays an important role as it protects the masonry from weathering agents and binds the bricks or blocks together to give strength and stability to masonry. Analysing the mortar prior to restoration ensures the stability of the masonry structures, and therefore increases the lifespan of the historical buildings. The analysis is done by means of different methodological approaches to identify the physical, chemical, mineralogical and mechanical properties, as will be discussed in the next section.

This paper reviews the literature related to characterisation of heritage cementing material components (binder and aggregates). This includes the challenges around the restoration of heritage cementing materials in South Africa. It excludes the analysis of any construction materials other than cementing materials, and does not discuss the effects of construction/ restoration technologies on the compatible restoration of heritage buildings.

\section{CHARACTERISATION OF HERITAGE CEMENTING MATERIALS}

Characterisation of historical mortars is a well-researched topic, dating as far back as the 1960s (Jedrzejewska 1960), and involves analysis and investigation on properties of hardened mortar and plaster collected from existing historical buildings. This process incorporates detailed experimental procedures for identification of the physical, chemical, mineralogical and mechanical properties of the plastering, rendering, bonding, bedding, laying and floor materials. However, Groot et al (2004), and Benedetti and Pelà (2012) highlighted the complexities around the experimental characterisation of the mechanical properties of mortars in existing masonry constructions. They stated that it requires the use of large sample quantities (to carry out standard testing on standard test specimens). In most cases mechanical characterisation becomes a challenge, as it is too risky for heritage authorities to allow extraction of large quantities of mortar from the joints of existing brickwork without causing disturbance to specimens and structures, hence the properties are very hard to acquire. Nonetheless, there are non-destructive testing (NDT) methods available to acquire the mechanical properties necessary without the collection of samples, as discussed in this section.

Characterisation of heritage mortars provides an answer to the question: What cementing material (type of binder, aggregates and additives) was originally used for the construction of the heritage building? The process assists with the design of replica materials, as shown in Figure 1. According to Hauková et al (2013), it is important to characterise not only historical building materials, but also modern materials, prior to restoration.

\section{Aesthetic characterisation}

This involves the performance of tests to evaluate the ancient building's mortar properties, such as visual appearance, colour, texture and surface finishing. This form of characterisation is performed by the naked eye, using a colour scale to define the colour of the mortar. In addition, some researchers use a stereo microscope to obtain detailed results on the material's aesthetic properties. Analysing the colour and texture of the original material is done to avoid a mismatch and to preserve the beauty represented by a specific colour or texture. In most decorative mortars, such as on historical sculptures and decorative plastering/ rendering, colour plays a significant role in

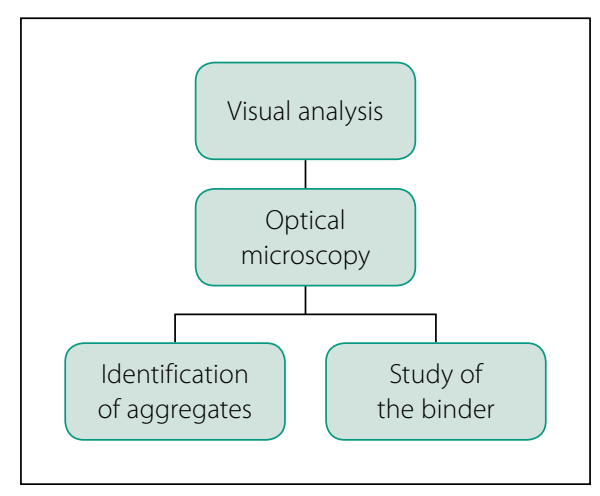

Figure 1 Mortar analysis procedure (Van Balen et al 1999) authenticity. Hence, use of material similar to the original material is encouraged. It is, however, important to bear in mind the possibility of change to the original colour and to the general material properties that could have been caused by ageing and weathering over the years. To get a sense of the original, or as close as possible to the original, the analysis is usually made on the inner/unexposed part of the mortar.

\section{Physical characterisation}

The physical analysis investigates the porosity properties of the mortars, such as open and total apparent density, frost resistance, water retention and particle size distribution. The physical properties of cementing materials assist in determining the aggregate type used during construction, which plays an important role during restoration when striving to achieve compatibility. To determine the grain distribution, the mortar is passed through a set of sieves before and after being exposed to hydrochloric acid $(\mathrm{HCl})$, and then the cumulative percentage of materials passing the sieves is calculated. Apostolopoulou et al (2017) highlight the need to consider the effect of weathering and possible alterations on materials through the years, which could have an impact on the exact gradation curves of the original materials. They, however, conclude that the gradation curves of the restoration aggregates must be as close to the original as possible, regardless of the possible weathering on the original materials.

\section{Granulometry/sieve analysis}

The granulometry of aggregates is considered a key factor in determining the quality of the mortar mix (Borges et al 2010). The pattern in which soil particles are distributed in a mortar, and their relative sizes, are the indicators of mortar engineering properties, which include the load capacity and mechanical resistance, mortar cohesion and hardness, hydraulic conductivity, shrinkage, compressibility and shear strength (Arizzi \& Cultrone 2013; Cayme \& Asor 2017). Despite this, it is to be noted that engineering behaviour of mortars cannot be based entirely on the gradation of aggregates, but also on other factors such as effective stress, stress history, mineral type, plasticity and geologic origins of aggregates, among others.

\section{Mineralogical characterisation}

This characterisation process is used to assess the degree of hydration and present quantities of minerals, such as calcium 


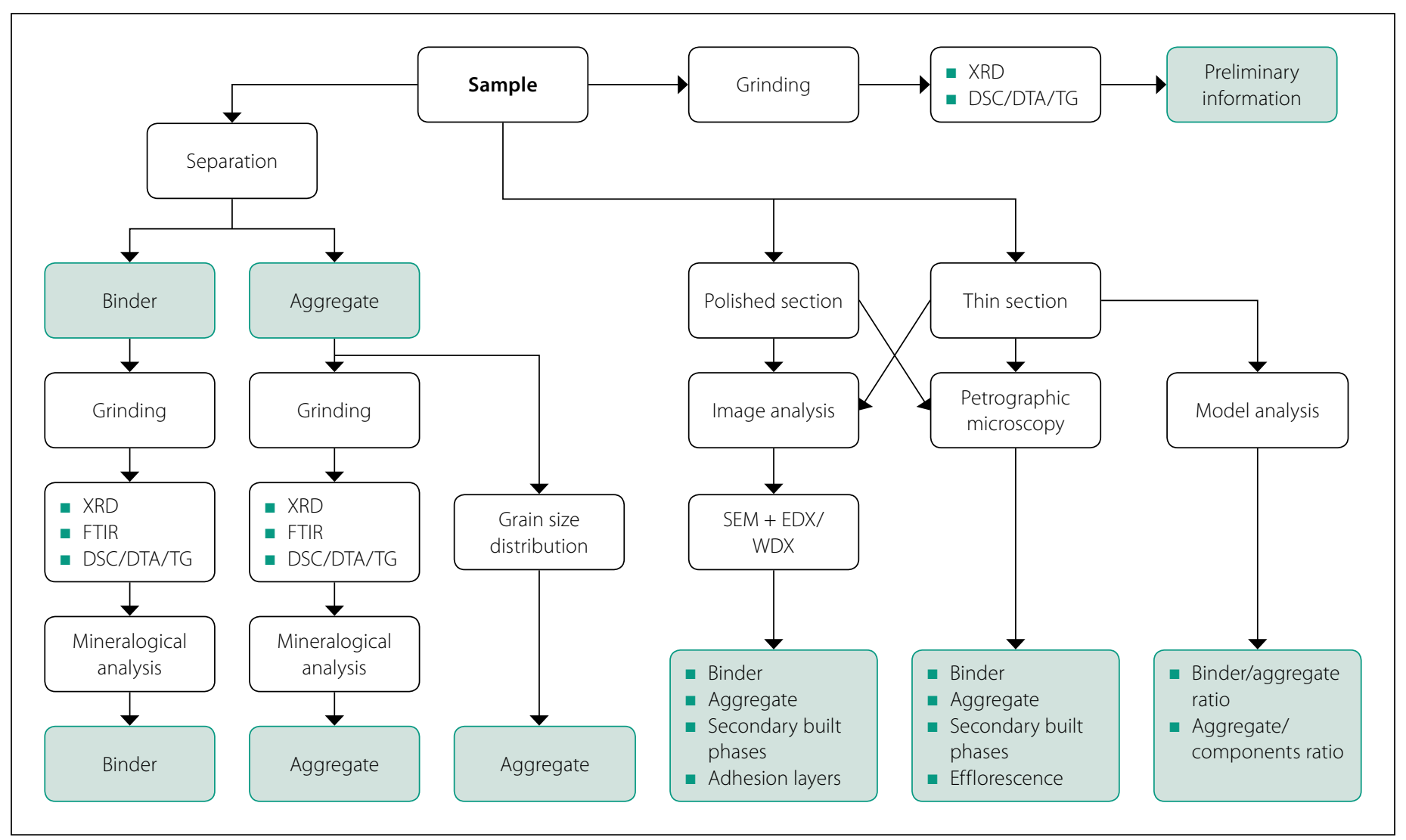

Figure 2 Flow chart for mineralogical characterisation (Middendorf et al 2005a)

hydroxide $\left(\mathrm{Ca}(\mathrm{OH})_{2}\right)$, calcite $\left(\mathrm{CaCO}_{3}\right)$, quartz $\left(\mathrm{SiO}_{2}\right)$, gypsum $\left(\mathrm{CaSO}_{4} 2 \mathrm{H}_{2} \mathrm{O}\right)$, albite $\left(\mathrm{NaAlSi}_{3} \mathrm{O}_{8}\right)$ and muscovite $\left(\mathrm{KAl}_{2}\left(\mathrm{AlSi}_{3} \mathrm{O}_{10}\right)(\mathrm{FOH})_{2}\right.$. These minerals play an important role in the way a mortar behaves and reacts with the surrounding environment. They are identified using a technique referred to as x-ray diffraction (XRD) analysis. This method clearly shows the crystalline phases that took place in the binder by determining the mineralogy of clays in the soil. Thermogravimetric analysis (TGA) is used to assess the degree of hydration in a mortar sample, while Fourier transform infrared spectrometry (FT-IR) gives the ratio between the $\mathrm{CaCO}_{3}$ and $\mathrm{SiO}_{2}$ content. In addition to the above minerals, Lopez-Arce et al (2016) performed ion chromatography (IC) to identify both soluble anions and cations such as chlorides $\left(\mathrm{Cl}^{-}\right)$and sodium $\left(\mathrm{Na}^{+}\right)$ in parts per million (ppm). Middendorf et al (2005a; 2005b) summarised the procedure for carrying out both mineralogical characterisation (Figure 2) and chemical characterisation (Figure 3).

\section{Chemical characterisation}

This stage identifies the chemical composition of the historical mortars. It is through the chemical characterisation that the type of binder used, and its quantity and the binder-to-aggregate ratio are identified.
Schueremans et al (2011) determined the chemical composition of mortar samples using different methods, such as wet chemical analysis and x-ray fluorescence (XRF). According to Schueremans et al (2011), using XRF only gives the chemical composition of the mortar constituents. The wet chemical analysis, which is carried out by dissolving the binder in a solution of diluted hydrochloric acid $(\mathrm{HCl})$, on the other hand, provides details of the chemical elements present in a sample. The oxides of chemical elements are quantified by use of absorption spectroscopy (AAS) or inductively coupled plasma optical emission spectroscopy (ICP-OES). The procedure for determining water soluble (Part II) and acid soluble chemical elements (Part I) in historical mortars is summarised in Figures 3(a) and (b).

The oxide percentages are useful for calculation of the cementation index (CI), as indicated in Equation 1.

$$
\mathrm{CI}=\frac{\left(2.8 \times \% \mathrm{SiO}_{2}+1.1 \times \% \mathrm{AI}_{2} \mathrm{O}_{3}+\right.}{\left.0.7 \times \% \mathrm{Fe}_{2} \mathrm{O}_{3}\right)}
$$

Where:

$\mathrm{SiO}_{2}=$ silicon oxide

$\mathrm{Al}_{2} \mathrm{O}_{3}=$ aluminium oxide

$\mathrm{Fe}_{2} \mathrm{O}_{3}=$ iron oxide

$\mathrm{CaO}=$ calcium oxide

$\mathrm{MgO}=$ magnesium oxide
According to Martínez et al (2013) and Brosnan (2014), the CI quantities as identified in Table 1 are an indication of lime and cement content in mortar samples.

Cayme and Asor (2017) carried out a simple and inexpensive complexometric titration test using ethylenediaminetetraacetic acid (EDTA) and potassium permanganate $\left(\mathrm{KMnO}_{4}\right)$ to quantify the amount of calcium in a mortar sample. According to Cayme and Asor (2017), it is important to quantify the amount of calcium, as it is a primary chemical element found in limebased mortars and is responsible for binding the stone and sand aggregates in a mortar.

\section{Mechanical characterisation}

The strength and stiffness properties of mortar in existing buildings are challenging to obtain, due to the limited quantity of samples obtainable from historical buildings. Therefore, Schueremans et al (2011) and Lawrence et al (2004) carried out non-destructive (NDT) surface tests using a pendulum Schmidt hammer and a scratch test respectively. The former provides information on mortar hardness, while the latter formulates a relationship between the scratch index and cement content. Benedetti and Pelà (2012) provided an example of obtaining mechanical properties using an in-situ penetrometer technique that is carried out to measure the energy required to 


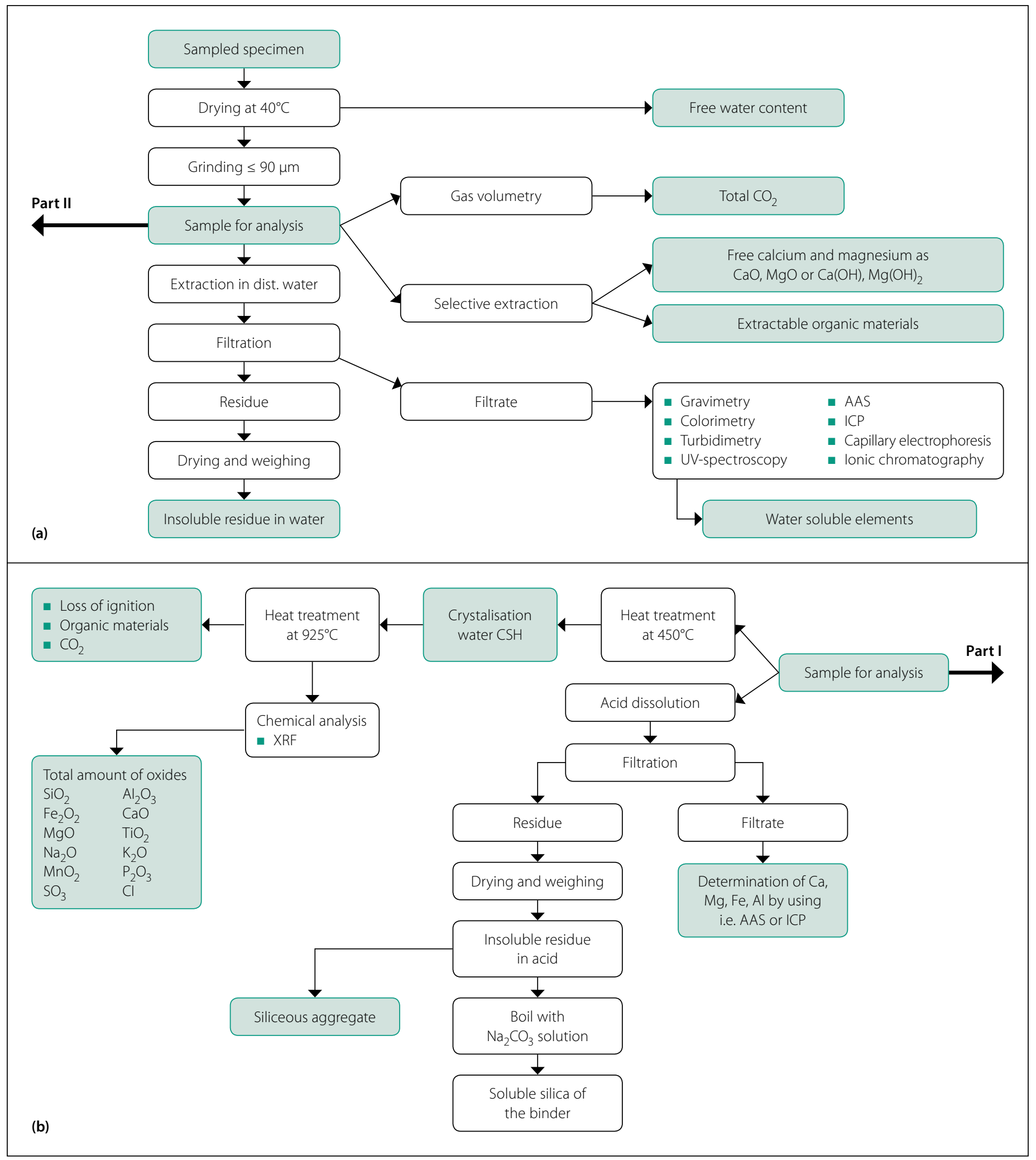

Figures 3 (a) and (b) Flow chart for chemical characterisation (Middendorf et al 2005b)

penetrate a masonry structure by means of drilling resistance. Due to scattered results, this technique requires caution when combining and analysing results. Other alternative NDTs include single or double flat jacks, the ultrasonic pulse velocity (UPV) test, and a rebar locator.

The characterisation methodology used for historical mortars, as per the reviewed literature, is summarised in Table 2, showing both field and laboratory
Table 1 Cementation index readings (Martínez et al 2013; Brosnan 2014)

\begin{tabular}{|l|c|c|}
\hline \multicolumn{1}{|c|}{ Binder description } & Cl & Active clay in the limestone \\
\hline Fat limes & Close to zero & - \\
\hline Pure (aerial) lime & $\mathrm{Cl}<0.15$ & Very little clay \\
\hline Sub-hydraulic lime & 0.15 to 0.3 & Very little clay \\
\hline Slightly hydraulic limes & 0.3 to 0.5 & Around $8 \%$ \\
\hline Moderately hydraulic limes & 0.5 to 0.7 & Around $15 \%$ \\
\hline Eminently hydraulic limes & 0.7 to 1.1 & Around $25 \%$ \\
\hline Natural cement & 1.7 & Up to 45\% \\
\hline
\end{tabular}


Table 2 Characterisation of historical mortars - methods
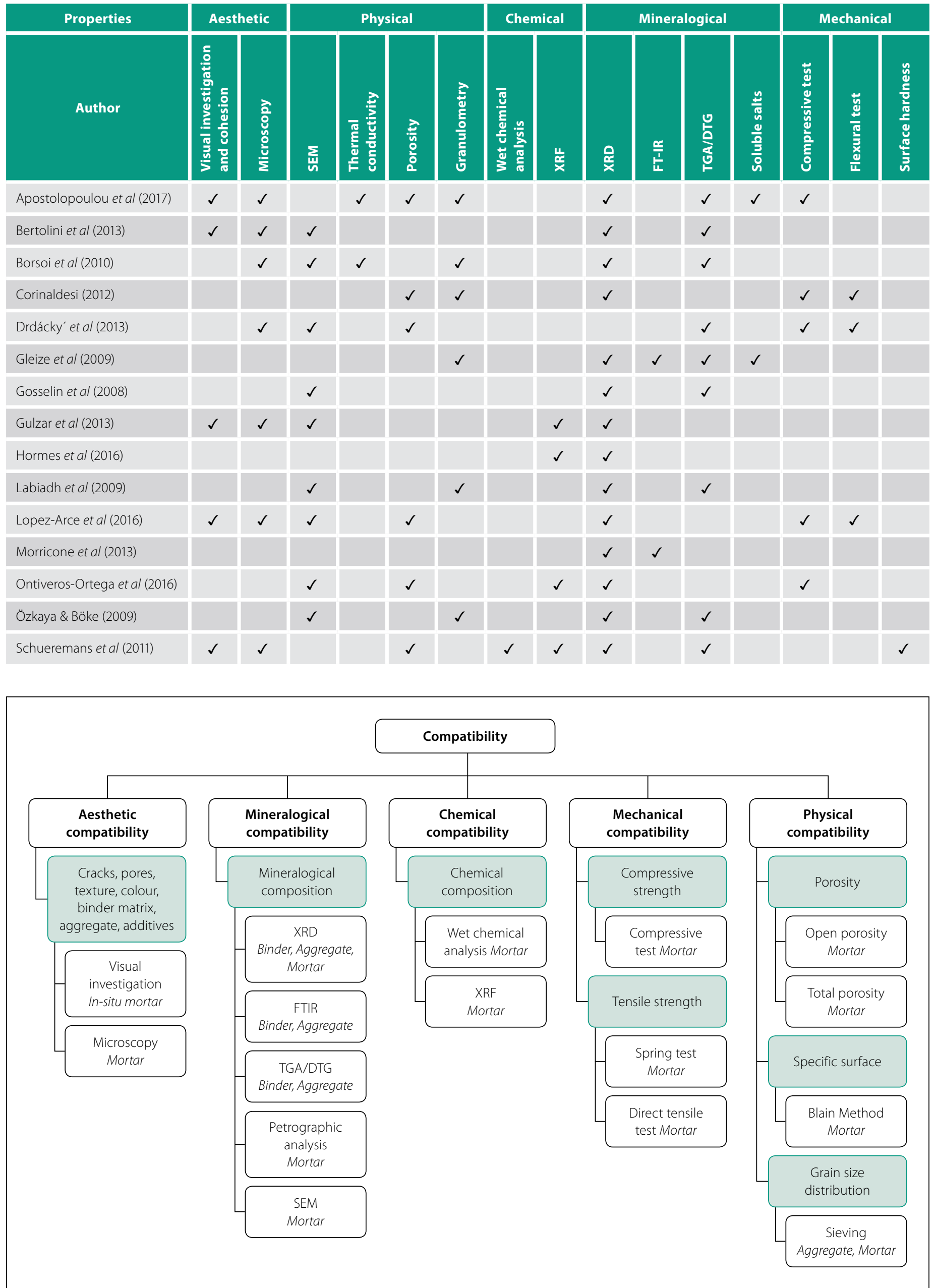
tests as conducted by numerous authors around the world. In addition to the tests shown in Table 2, there are other tests used that include electron probe analysis, the freeze-thaw test, salt crystallisation, indirect tensile and bending tests, moisture content, permeability, mercury intrusion porosimetry, the density and water saturation method, gas chromatography and hydrogen potential $(\mathrm{pH})$ tests. The choice of the characterisation technique could be affected by the damages present on the historical building in question.

\section{Compatibility assessment}

It is essential to assess the repair material compatibility with the original historical mortar by proper material characterisation (Bertolini et al 2013; Historic England 2018b). This is to guarantee the longterm durability and strength of historical structures. To overcome the compatibility challenges, Hormes et al (2016) emphasises the need to thoroughly study the material properties, as already mentioned above.

They suggest that material analysis assists in the production of a good repair mortar that would yield an aesthetic, chemical and mineral match of the cementing material used originally. Schueremans et al (2011) summarised the overall common characterisation tests for achieving compatibility of historical mortars, as depicted in Figure 4.

\section{RESTORATION OF HERITAGE CEMENTING MATERIALS}

Sandbhor and Botre (2013) define restoration as: “... the act or process of accurately depicting the form, features and character of a property as it appeared at a particular period of time." According to Fang et al

(2015), the conservation and preservation of heritage buildings should be a focal subject, since heritage buildings represent the beauty of the country and its history. Some heritage structures are seen to be safety hazards, as they have deteriorated severely and are at risk of collapsing. The South African Castle of Good Hope (built in 1666), located in Cape Town, is an example of a heritage building that was in severe structural deterioration facing collapse in the early 20th century (Gilbert 1994). The status of this historical building led to the appointment of Gabriel Fagan (South African award-winning architect) by the then Department of Public Works to carry out full restoration in the 1960s to what we see today (Cape Business News 2016). According to Fagan, there are many reasons for the restoration of historical buildings, including economics and preservation of culture.

The continued existence of heritage buildings is usually achieved through the use of materials which match the original ones (Gulzar et al 2013). However, matching the materials on historical buildings is more challenging than it is on modern structures (Penelis 1996). The former requires a sensitive approach to preserve the original fabric of heritage structures. The success of restoration work depends on the knowledge of the original materials that is achievable through original material characterisation as discussed above. On the other hand, Dolar-Mantuani (1984) emphasises the need to consider not only the appearance of the material, but also the properties (strength, adhesion, flexibility and porosity) and its future maintenance. He further states that the negative comebacks associated with inappropriate or poor execution of repairs of historical mortars include premature damage and accelerated deterioration of the original building fabric. This lack of understanding of original materials leads to more damage during restoration of heritage buildings, which increases the cost of future maintenance and repair works.

Based on a study by Danieli and Bloch (2012), conservation and restoration of historical buildings have been explored by many researchers, mainly in seismic regions. Restoration technologies such as straining beams, carbon fibre cords, reinforcement systems consisting of carbon fibre tapes and epoxy resins (structural reinforcement system), cement or polymer solution masonry injection, polymer grids, concrete spraying, reinforced concrete jackets, and reinforced concrete are mentioned in their study. There are, however, no publications in this field in the South African context.

Papayianni and Pachta (2017) indicated that the use of compatible and locally available materials has been introduced for the restoration of old earth-block masonry buildings. This includes the development of effective repair materials and techniques to utilise when repairing historical structures. Lourenço (2006) raised a concern as far as durability, strength and architecture in restoration are concerned. He highlights the importance of differentiating between the science of construction, and the art of conservation and restoration, as these two are considered independent aspects that require separate approaches. The repair and restoration of heritage structures is a major challenge, as most of these structures were built using materials that are no longer commonly used. The common practice used for the restoration of heritage cementing materials is through the application of modern Portland cement, but numerous shortcomings of this approach have been identified (Lanas \& Alvarez 2003). Compared to Roman concrete, Portland cement is said to be quick to crack and corrosive to the original material, and has high compressive strength, high modulus, a large thermal expansion coefficient, and low porosity which hinders water movement and air circulation in the masonry, leading to intensified damage (Marini et al 2018; Fang et al 2015; Martínez et al 2013; Gleize et al 2009; Lanas \& Alvarez 2003; RodriguezNavarro et al 1998).

To avoid causing harm to the original material during the restoration of historical mortars, Singh et al (2014) and Apostolopoulou et al (2017) suggested the inclusion of information on aesthetic and material compatibility (chemical, physical and mechanical). These studies mentioned that several researchers fail to explain the context of compatibility when it comes to restoration of historical mortars. In addition, there are general performance requirements to be considered when selecting repair mortars, which include authenticity, reversibility, compatibility, retreatability, function, technology and durability (Schueremans et al 2011). According to Apostolopoulou et al (2017), in order to keep heritage buildings looking as original as possible after restoration, the following stages must be followed: diagnosis and safety, authenticity, compatibility and heritage preservation.

\section{Diagnosis and safety}

Croci (2000) and Lourenço (2006) define diagnosis and safety as the principal stages of the restoration procedure describing the nature of deformities, be it cracks or decay that are currently visible on heritage buildings. Diagnosis and safety are most important, as they give the restorer knowledge about the degree of harm on a structure, thereby ensuring that precise mitigation measures are applied. It is never simple to remedy defects with no basis of what the defects are and their precise cause. Before completing any construction works, restoration included, safety associated with the works to be carried out ought to be evaluated. Diagnosis and safety are interrelated, although they vary somewhat. It is 


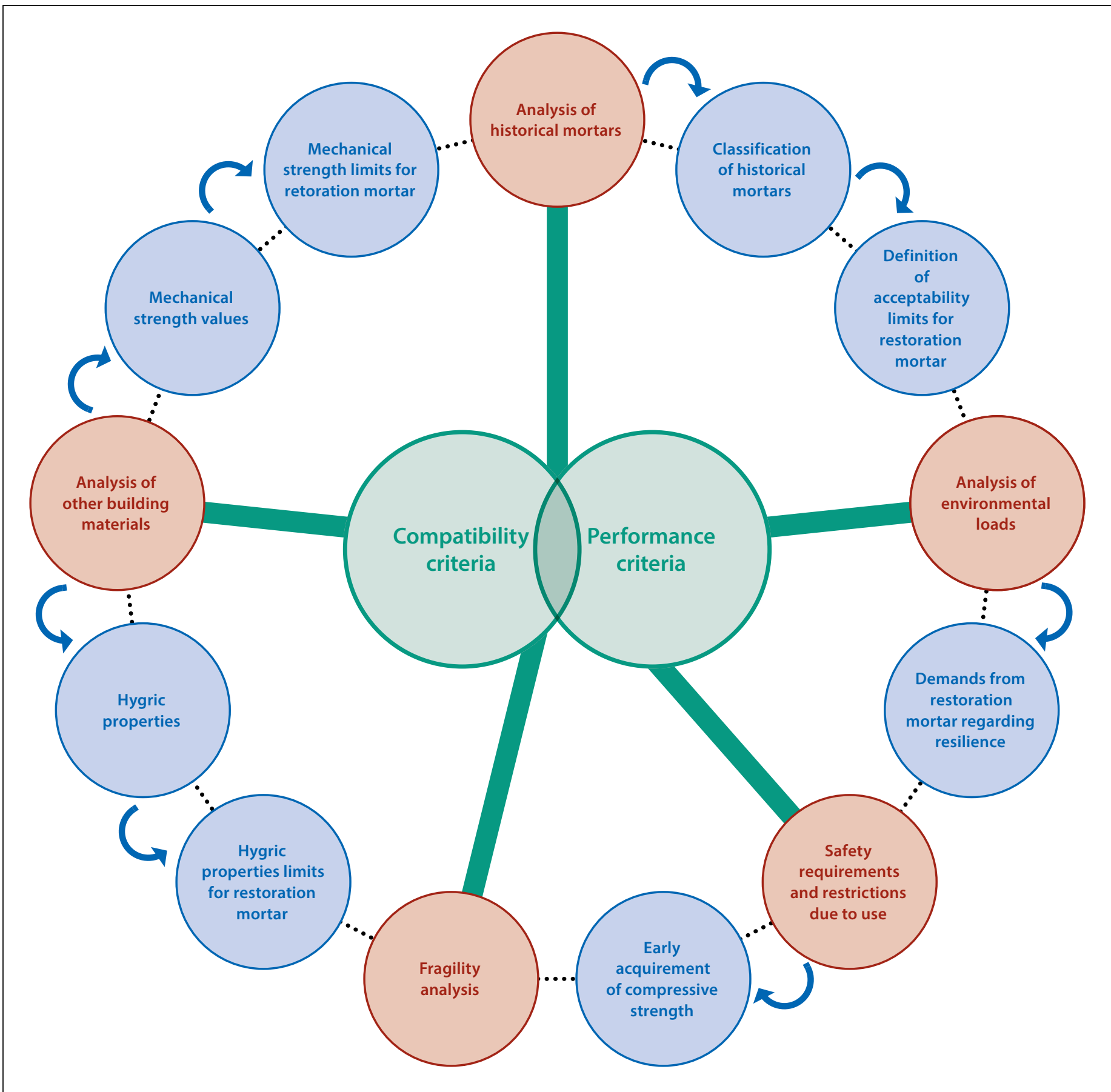

Figure 5 Compatibility and performance criteria (Apostolopoulou et al 2017)

mentioned that diagnosis is associated with the past, while the latter is connected to the current situation of the structure after repairs have been completed (Croci 2000; Lourenço 2006).

\section{Authenticity}

Restoration of heritage structures comes with high expectations of authenticity, hence modifications to the structure are expected to be minimal to zero where possible. According to Apostolopoulou et al (2017), authenticity is the trickiest aspect to achieve, as some of the materials originally used do not exist anymore. Even though this is the case, authenticity plays an important role and should be achieved as far as possible throughout the entire restoration process, regardless of the challenges faced in achieving this.

\section{Compatibility}

Isebaert et al (2014) describe compatibility as "... utilising materials that do not have negative consequences on the original materials." The definition is based on the original mortar characteristics which are compared to the repair mortars. Schueremans et al (2011) reckon that the repair mortars and techniques should match the original under the given circumstances in terms of physical, mechanical and chemical properties, as well as design and application. Knowledge of these aspects simplifies predictions regarding the reaction of the historical structure to the applied restoration materials (Singh et al 2014). The relationship between performance and compatibility is shown in Figure 5.

\section{Historical preservation}

Apostolopoulou et al (2017) stated that preserving the history of the heritage buildings can be achieved through minimal alterations during repairs, and the restoration team (made up of representatives from different fields) ought to retain the historical value that heritage buildings hold whenever any alterations have to be made. This is, however, not always the case, as materials change from time to time. 


\section{Principles governing restoration}

Podiapolski et al (1988) showed the different techniques to carry out historical structure preservation, which include maintenance, conservation and restoration. The authors indicated that, different as these are, they may include similar techniques. The primary purposes of maintenance are to prevent loss of structural integrity and to prolong the structure's durability, and these need to be handled with caution.

\section{Restoration standards}

The Department of Archaeology and Historic Preservation of the United States, through the Secretary of the Interior's Standards and Guidelines, has set standards for restoration and preservation of historical buildings (Sandbhor \& Botre 2013). These are as follows:

- The historical character of a property should be reserved and preserved in a way that replacement of materials does not alter the features, spaces and spatial relationships that characterise the property.

- Each property ought to represent the original material and the use of the building. Any work aimed at restoring historical materials need to be good, identifiable and legitimately archived for future research.

- Distinctive materials, highlights, completions and development methods, or cases of craftsmanship that portray the property, ought to be saved.

- The existing state of notable highlights ought to be assessed to decide the proper level of mediation required. Mediations that cause harm to notable materials should not be utilised.

- Deteriorated notable highlights ought to be repaired instead of replaced. Where the seriousness of weakening requires substitution of an unmistakable component, the new element should coordinate the old in configuration, shading, surface and materials. Substitution of missing materials ought to be validated by narrative and physical confirmation.

- New improvements or modifications should be done in a way that, if abandoned later on, the originality of the monument is preserved and not tampered with.

- Replacement of materials from the original time of construction ought to be verified by documented proof that they would match the existing, or not cause any harm to the original surface. There should be no inclusion of assumed highlights of history, highlights from different properties, or joining highlights that never existed together originally.

- Restoration ought to be done to portray the missing components or sections of a building and should be done in a way that shows precise history of what was used initially (exact duplication of materials).

- A restored property should be similar in terms of materials, plan, shading and surface to the original one (Archaeology and Historic Preservation 2018).

Mata (2009) agrees with the standards set out above, as he mentions the need for returning the building to its original beauty and form during restoration. In his report he states that, for restorers to achieve authenticity on historical buildings, it is important to carry out a thorough material analysis.

A number of restoration projects on heritage structures have been conducted worldwide. Some examples are summarised in Table 3.

South Africa is not an exception, as several restoration projects, such as the Castle of Good Hope, the proposed restoration of building precincts at Robben Island, restoration of the SAAO, Parliament, and the Church Street houses in Tulbagh (all in the Western Cape Province), the Owl House Museum in Nieu-Bethesda (Eastern Cape), and many more have been conducted in the past, and some are at proposal stage. The South African National Heritage Resources Act, No 25 of 1999 (Republic of South Africa 1999), outlines the following fundamental elements to consider while carrying out restoration work on heritage structures:

- No individual or association is permitted to endeavour any restoration works without obtaining the related licences from the Municipality and the Provincial Heritage Resources Authority.

- Restorers must seek advice from a professional building and restoration advisor before attempting any restoration works. The issuing of a permit by the South African Heritage Resources Agency (SAHRA) can only be guaranteed when such review and advice are provided by experts within the area concerned (Republic of South Africa 1999).

However, the legislation does not fully detail the need for restorers to analyse original materials prior to execution of restoration work on heritage buildings. The lack of material analysis enforcement has resulted in unsuccessful restoration projects (examples to be discussed further on in this paper).

\section{Heritage restoration techniques}

Restoration and repair of historic structures require the use and application of proper material and restoration techniques (Deshpande 2017). According to Penelis et al (1989), there are two techniques (reversible and irreversible) which the restorer must choose from when carrying out repair work. Not only effectiveness, but also economic viability ought to be considered when restoring heritage buildings. One of the oldest, yet irreversible, methods for repairing heritage buildings is grouting, which involves filling of cracks and voids inside the mass of earth stonework. However, introducing Portland cement has altogether changed the conduct of the grouted parts of the masonry. It affects deformability and reaction to porosity and hydrothermal loading properties, as the mortar is either extremely strong or hard, thus making it inflexible and impermeable, or it has a large thermal expansion coefficient (Papayianni \& Pachta 2014). Both ancient and modern techniques can be useful in the restoration of historical buildings, but with careful consideration.

According to Croci (2000), maintaining historical buildings requires the use of original materials and techniques rather than modern ones. This makes it quite easy to obtain authenticity on the heritage structures. New procedures in the restoration of buildings need to be used with great caution, since their misuse can cause irreversible harm (Croci 2000). As per Croci (2000), advanced modern practices, for example the inclusion of steel bars and infusion of bond mortars, are irreversible and result in negative reactions, such as corrosion of steel bars and efflorescence due to the salts present in Portland cement, which can damage structures. It is also mentioned that it is possible that these might change the original status of the monument.

\section{Effective restoration}

When restoration of structures is done properly, it extends the lifespan of the structure by enhancing its strength and enabling it to withstand external forces such as weather and chemical reactions that cause decay. The delay in restoring a 


\begin{tabular}{|c|c|c|c|c|c|c|}
\hline Author & Location & Type of structure & $\begin{array}{c}\text { Age } \\
\text { (century) }\end{array}$ & $\begin{array}{l}\text { Material } \\
\text { tested }\end{array}$ & $\begin{array}{l}\text { Samples } \\
\text { tested }\end{array}$ & Results and analysis \\
\hline $\begin{array}{l}\text { Apostolopoulou } \\
\text { et al (2017) }\end{array}$ & Greece (Europe) & Church & $12^{\text {th }}$ & $\begin{array}{l}\text { Internal and } \\
\text { external mortar }\end{array}$ & 10 & $\begin{array}{l}\text { High porous lime-based mortars with minor } \\
\text { additions of organic admixtures. }\end{array}$ \\
\hline $\begin{array}{l}\text { Bertolini et al } \\
\text { (2013) }\end{array}$ & Italy (Europe) & Church & $\begin{array}{l}4^{\text {th }} \text { and } \\
5^{\text {th }}\end{array}$ & Mortar & 40 & $\begin{array}{l}\text { Binder was mainly based on magnesian lime. } \\
\text { Gypsum was found in most samples. }\end{array}$ \\
\hline Borsoi et al (2010) & Portugal (Europe) & Archaeological site & I-IV AD & Mortar & 11 & $\begin{array}{l}\text { Traces of aerial calcitic lime with quartz, schistose } \\
\text { and granitoid aggregates and artificial pozzolanic } \\
\text { materials. }\end{array}$ \\
\hline $\begin{array}{l}\text { Drdácky' et al } \\
\text { (2013) }\end{array}$ & Italy (Europe) & Roman arch bridge & $27 \mathrm{BC}$ & Roman mortars & 4 & The strongest mortar was used. \\
\hline Gleize et al (2009) & $\begin{array}{l}\text { Brazil } \\
\text { (South America) }\end{array}$ & $\begin{array}{l}\text { Nine historical } \\
\text { buildings in the State } \\
\text { of Santa Catarina }\end{array}$ & $18^{\text {th }}-20^{\text {th }}$ & $\begin{array}{l}\text { Rendering } \\
\text { mortars }\end{array}$ & 9 & $\begin{array}{l}\text { Hydrated lime obtained from the burning of } \\
\text { seashells was the major binder. It was sometimes } \\
\text { mixed with hydraulic materials (clay, ground } \\
\text { ceramic tile or brick, and hydraulic lime). }\end{array}$ \\
\hline $\begin{array}{l}\text { Gosselin et al } \\
(2008)\end{array}$ & France (Europe) & Cathedral & $11^{\text {th }}$ & $\begin{array}{l}\text { Pointing } \\
\text { material }\end{array}$ & 11 & $\begin{array}{l}\text { Old mortars show traces of siliceous and } \\
\text { carbonate aggregates. }\end{array}$ \\
\hline Gulzar et al (2013) & Pakistan (Asia) & Mughal empire & $17^{\text {th }}$ & $\begin{array}{l}\text { Plaster and } \\
\text { mortar }\end{array}$ & 7 & $\begin{array}{l}\text { Calcitic lime binder produced from calcinations of } \\
\text { kankar- } \mathrm{CaCO}_{3} \text { from soil horizon. The aggregates } \\
\text { included crushed bricks, broken kankar pieces, } \\
\text { brick kiln furnace slag and a small fraction of } \\
\text { siliceous sand. }\end{array}$ \\
\hline $\begin{array}{l}\text { Hormes et al } \\
\text { (2016) }\end{array}$ & $\begin{array}{l}\text { Germany } \\
\text { (Europe) }\end{array}$ & Cathedral & $13^{\text {th }}$ & Mortar & 3 & $\begin{array}{l}\text { High concentration of iron, comparable to that of } \\
\text { calcium. }\end{array}$ \\
\hline $\begin{array}{l}\text { Labiadh et al } \\
\text { (2009) }\end{array}$ & Tunisia (Africa) & $\begin{array}{l}\text { Ottomans } \\
\text { monuments }\end{array}$ & $15^{\text {th }}$ & $\begin{array}{l}\text { Waterproof- } \\
\text { coating mortars }\end{array}$ & 2 & $\begin{array}{l}\text { Presence of air-hardening lime, pozzolanic and } \\
\text { gypsum indicating sulfatic but free of ettringite. }\end{array}$ \\
\hline $\begin{array}{l}\text { Lopez-Arce et al } \\
\text { (2016) }\end{array}$ & France (Europe) & $\begin{array}{l}\text { Exhibition hall and } \\
\text { museum }\end{array}$ & $18^{\text {th }}$ & Plaster mortars & 9 & $\begin{array}{l}\text { Traces of gypsum, calcium and sodium sulfates, } \\
\text { and minor amounts of nitrates were found in } \\
\text { mortar. }\end{array}$ \\
\hline $\begin{array}{l}\text { Morricone et al } \\
\text { (2013) }\end{array}$ & $\begin{array}{l}\text { Rome, Italy } \\
\text { (Europe) }\end{array}$ & $\begin{array}{l}\text { Archaeological site of } \\
\text { Porta Marina }\end{array}$ & $3^{\text {rd }} B C$ & $\begin{array}{l}\text { Pointing } \\
\text { material }\end{array}$ & 25 & $\begin{array}{l}\text { Aggregates present in the mortars are essentially } \\
\text { pozzolanic. }\end{array}$ \\
\hline $\begin{array}{l}\text { Ontiveros-Ortega } \\
\text { et al (2016) }\end{array}$ & Spain (Europe) & Theatre & $4^{\text {th }} B C$ & $\begin{array}{l}\text { Substructure } \\
\text { mortars }\end{array}$ & 14 & $\begin{array}{l}\text { Presence of lime nodules in the mortar, calcareous } \\
\text { crust. }\end{array}$ \\
\hline $\begin{array}{l}\text { Özkaya \& Böke } \\
\text { (2009) }\end{array}$ & Turkey (Europe) & Temple & $1^{\text {st }} \mathrm{BC}$ & Wall mortars & 2 & $\begin{array}{l}\text { Pure lime, coarse aggregate particle sizes }>1 \mathrm{~mm} \\
\text { and pozzolanic fine aggregates in Roman mortars. }\end{array}$ \\
\hline $\begin{array}{l}\text { Schueremans } \\
\text { et al (2011) }\end{array}$ & Belgium (Europe) & $\begin{array}{l}\text { Two churches and } \\
\text { castle }\end{array}$ & $\begin{array}{l}4^{\text {th }} \text { and } \\
12^{\text {th }}\end{array}$ & $\begin{array}{l}\text { Pointing } \\
\text { material }\end{array}$ & $9,6,3$ & $\begin{array}{l}\text { Relatively similar properties - carbonation of lime in } \\
\text { the pointing material. }\end{array}$ \\
\hline
\end{tabular}

structure is detrimental, as the condition of the structure can worsen to such a degree that it becomes exceptionally hard to recapture its original unique condition (Sandbhor \& Botre 2013). Croci (2000) has therefore suggested that surveys be conducted to identify the problems, assess the safety implications, and study and choose the criteria and techniques to employ for remedying the problem. His advice is that restorers need to keep a very close eye on every activity taking place during repairs of historical monuments, as restoration is a delicate process that should be handled with care.

Podiapolski et al (1988) indicated that effective repair of historical buildings requires knowledge of the following:

- Building functionality and why its materials are beginning to fail, and
- What would be possible remedial measures to avoid future encounters of failure. They emphasise the importance of observing the different problems for different structures of a particular time which exhibit distinctive issues. The practice of inappropriate repairs may cause early failure and accelerate the weakening of original material, thus expanding the degree and cost of future rehabilitation and repair projects (Podiapolski et al 1988).

\section{Heritage restoration materials}

The determination of materials for the repair of heritage structures is dependent on factors such as the necessity of repairs, the cost, and the behaviour of materials in the repair of structural defects. To carry out a successful repair that will enhance the damaged building's structural strength, there are key factors that one needs to adopt. These include innovative repair materials which have good workability, and appropriate repair methods and practices of which the quality needs to be monitored throughout the implementation process (Deshpande 2017). The selection is carried out based on both cementitious and non-cementitious materials. However, Papayianni and Pachta (2014) advised on the use of similar or close-to-original materials during restoration. They mentioned that, for lime-mortar structures, limebased repair materials instead of Portland cement are an ideal option. It is acceptable to replace Portland cement with enhanced natural hydraulic lime (NHL), which is far more compatible with the original materials on most lime mortar historical buildings (Marini et al 2018). 
According to Papayianni and Pachta (2014), restoration of earth-block structures could be done using grouts made of clayey material. This type of repair material helps to achieve the similarity between the original and the repair materials. However, there is usually a difference in properties (strength and appearance) of the repaired parts of the structure when using these repair mortars. Deshpande (2017) outlined the use of shotcrete, epoxy resins, epoxy mortars, gypsum cement mortars, fast-setting cement mortars and mechanical anchors for the restoration of heritage structures. In addition to these, he elaborated that there are distinctive natural materials which were used in the past, for example rice husk, jute fibres, glue, paste, jaggery and concentrates of numerous plants. These materials were found to decrease the odds of mortars breaking down, and also provided increased binding capacity. However, the construction industry at present has abandoned the use of some of these materials, rather using new materials (Deshpande 2017).

\section{HERITAGE RESTORATION CHALLENGES - SOUTH AFRICA}

Heritage restoration requires a detailed survey before one can execute the actual physical work. It has been established during numerous interviews with the SAHRA built environment unit that most heritage restorers still lack understanding about authenticity when dealing with heritage restoration. This has resulted in failures on some previous restoration works, as material analysis was generally either not done completely or done incorrectly (Mwasinga 2018). Another challenge facing South African heritage restoration is lack of clarity in terms of role players in the restoration and conservation of historic buildings. According to Feilden (2003), it takes a team of specialists from different fields to carry out a successful conservation and restoration project. These role players include archaeologists, architects, conservators, contractors, material scientists, and civil and structural engineers, among others. Feilden (2003) also mentions that the majority of engineers do not fully understand the complexity of restoring historical buildings. He suggests that conservation courses be made available to engineers prior to engagement in restoration projects.

According to SAHRA archive reports, there are a number of restoration projects which failed dismally due to the use of incorrect restoration materials. These include the restoration of sculptures at the Owl House Museum in the Eastern Cape Province. According to the 2018 museum site report (SAHRA 2018b), a type of cement different to the original was used in 2010 to fill cracks on the sculptures. This practice had caused further damage to the sculptures and a resulting loss of the original authenticity. The report added that the conservation management plan (CMP) had not included clear details on original material analysis for compatibility with new material (Mwasinga 2018).

The other case is the repointing at Robben Island (SAHRA 2018a). This World Heritage Site was repointed in around 1999. However, the conditional assessment report (SAHRA 2018a) for the restoration of the selected buildings on the island indicated the need to assess the composition of the original materials. The report further showed that some of the buildings appeared to have lost their historical features, due to previous maintenance which had not considered air circulation within the wall structures. The conclusion of this report was that the plaster and raised pointing of most of the buildings needed to be removed, due to the apparent use of silicone and Portland cement, both of which were considered to be detrimental to the overall fabric. The Portland cement repointing was said to prevent air circulation within the masonry. It was therefore recommended to replace the plaster and the pointing material with lime-base materials which, it had been discovered, were the original laying mortars.

\section{SUMMARY}

Due to the positive impact that historical structures have on the history, culture and economy of countries, their care and maintenance are considered very important for their continued existence. Characterisation of heritage cementing materials for restoration purposes has been explored extensively on a global scale. However, there is no literature related to this topic in South Africa. This leads to the application of incompatible materials for restoration, as discussed in the section above. It is clear that the originally used materials can only be identified through experimental characterisation, as there are no reliable tests and data available on the original mortars. For aesthetic characterisation of historic mortars, an approximate $33 \%$ of the researchers reviewed in this paper conducted visual investigations with the naked eye, while an additional 14\% went further to analyse the mortars by using stereo microscopes. The results for both show the particle distribution of the polished mortar samples and the additive fragments at magnification for most historical mortars. In determining the physical properties, approximately $60 \%$ of the researchers used a scanning electron microscopy (SEM) technique, $13 \%$ measured the thermal conductivity of the samples, and 40\% measured open and total porosity as well as granulometry. In terms of mineral identification in mortars, the majority (93\%) of the studies used XRD analysis, while only 13\% assessed the $\mathrm{CaCO}_{3} / \mathrm{SiO}_{2}$ ratio.

\section{CONCLUSIONS}

The critical areas that have received less attention and need to be addressed by future researchers in the field of heritage cementing materials and restoration of heritage buildings are discussed in this section. No literature could be found on studies providing a standard procedure to characterise heritage cementing materials in South Africa and across Africa. If specific methodologies can be implemented and incorporated into conservation management plans, under the material analysis of original materials, the investment in such research would be worthwhile, as it would help augment the life span of historical buildings through compatible restoration.

Mechanical properties of cementing materials need to be investigated prior to restoration works. This would guide the restorers in terms of the suitability of repair materials. Research should therefore not only be limited to the analysis of physical, chemical and mineralogical properties, but also to mechanical properties through non-destructive testing. This area has received no attention whatsoever in South Africa. In addition, even though aesthetic properties of heritage structures play a huge role in tourist attraction, this aspect has not been well addressed in terms of matching the colour of the original materials to that of current repairs. The details regarding how to avoid a mismatch, not only for the present time, but also for future years, has not been investigated.

There is also a need to integrate the general construction material analysis and construction techniques used for historical 
buildings, as this would assist in choosing the techniques suitable for restoration of the historical structures in question. In the South African context, no literature is available for systematic characterisation of heritage materials from any given era.

The literature that was reviewed clearly showed that no information is available on characterising materials in time periods (e.g. the 1600s, 1700s, 1800s or 1900s), nor in regional differences or the additional complications caused by such differences. For South Africa, the implementation of a characterisation methodology that is affordable and practical in terms of equipment and complexity should be encouraged. This will ensure material analysis practices which will extend the lifespan of historical buildings. The engagement of all stakeholders and experts from different fields will ensure the sustainable restoration of historical buildings, not only in South Africa, but in most developing countries.

\section{ACKNOWLEDGEMENTS}

The authors wish to acknowledge the financial support provided by the government of the Kingdom of Lesotho for the on-going project. The support granted by the South African Heritage Resources Agency (SAHRA) through provision of access to heritage sites, as well as to their archives, is highly appreciated. The authors further wish to express their gratitude to the South African Institute for Heritage Science and Conservation (SAIHSC) and the reviewers of this paper for sharing their expertise and providing valuable comments and suggestions.

\section{REFERENCES}

Apostolopoulou, M, Aggelakopoulou, E, Siouta, L et al 2017. A methodological approach for the selection of compatible and performable restoration mortars in seismic hazard areas. Construction and Building Materials, 155: 1-14.

Archeology and Historic Preservation: Secretary of the Interior's Standards and Guidelines 2018. Available at: http://www.cr.nps.gov/local-law/ arch_stnds_8_2.htm (accessed in May 2018).

Arioglu, N \& Acun, S 2006. A research about a method for restoration of traditional lime mortars and plasters: A staging system approach. Building and Environment, 41: 1223-1230.

Arizzi, A \& Cultrone, G 2013. The influence of aggregate texture, morphology and grading on the carbonation of non-hydraulic (aerial) lime-based mortars. Quarterly Journal of Engineering Geology and Hydrogeology, 46: 507-520.

Benedetti, A \& Pelà, L 2012. Experimental characterization of mortar by testing on small specimens. Proceedings, 15th International Brick and Block Masonry Conference, Florianópolis, Brazil.

Bertolini, L, Carsana, M, Gastaldi, M, Lollini, F \& Redaelli, E 2013. Binder characterisation of mortars used at different ages in the San Lorenzo Church in Milan. Material Characterization, 80: 9-20.

Borges, C, Santos Silva, A \&Veiga, R 2010. Ancient mortars under action of marine environment: $\mathrm{A}$ physico-chemical characterization. Proceedings, 2nd Conference on Historic Mortars - HCM 2010 \& RILEM TC 203-RHM Final Workshop, 22-24 September 2010 Prague, Czech Republic, pp 29-41. Borsoi, G, Silva, A S, Menezes, P, Candeias, A \& Mirão, J 2010. Chemical, mineralogical and microstructural characterization of historical mortars from the Roman villa of Pisoes, Beja, Portugal. Proceedings, 2nd Conference in Historic Mortars - HMC 2010 \& RILEM TC 203-RHM Final Workshop, 22-24 September 2010, Prague, Czech Republic.

Brosnan, D A 2014. Characterization and degradation of masonry mortar in historic brick structures. Journal of Structures, Vol 2014, Article ID: 859879, pp 1-7, doi:10.1155/2014/859879. Hindawi Publishing Corporation.

Cape Business News 2016. Experts oversee repairs on the Cape's oldest building, 13 April 2016. Available at: https://www.cbn.co.za/news/experts-overseerepairs-on-the-cape-s-oldest-building (accessed in May 2019).

Cayme, J M C \& Asor, A N 2017. Calcium content of lime mortars from 9th century church ruins in the Philippines using volumetric analysis. Malaysian Journal of Analytical Sciences, 21(5): 1080-1090.

Corinaldesi, V 2012. Environmentally-friendly bedding mortars for repair of historical buildings. Construction and Building Materials, 35: 778-784.

Croci, G 2000. General methodology for the structural restoration of historic buildings: The cases of the Tower of Pisa and the Basilica of Assisi. Journal of Cultural Heritage, 1(1): 7-18.

Danieli, M \& Bloch, J 2012. Principle, practice and experience of rehabilitation of the historical buildings in seismic regions. Ariel University Center of Samaria, Ariel, Israel.

Deshpande, U L 2017. Repair, restoration and strengthening of buildings. International Journal of Innovations in Engineering Research and Technology, 4(3): 121-124.

Dolar-Mantuani, L 1984. Handbook of Concrete Aggregates, A Petrographic and Technological Evaluation. Park Ridge, NJ: Noyes Data Corporation, pp 79-125.

Drdácky', M, Fratini, F, Frankeova, D \& Sližková, Z 2013. The Roman mortars used in the construction of the Ponte di Augusto (Narni, Italy). A comprehensive assessment. Construction and Building Materials, 38: 1117-1128.

Fang, S, Zhang, K, Zhang, H \& Zhang, B 2015. A study of traditional blood lime mortar for restoration of ancient buildings. Cement and Concrete Research, 76: 232-241.

Feilden, B M 2003. Conservation of Historic Buildings, 3rd ed. Oxford, UK: Taylor \& Francis.

Gilbert, C 1994. The Castle of Good Hope: An examination of controversies and conflicting perceptions. A case study in public history. BA (Hons) report, University of Cape Town.

Gleize, P J P, Motta, E V, Silva, D A \& Roman, H R 2009. Characterization of historical mortars from Santa Catarina (Brazil). Cement and Concrete Composites, 31: 342-346.

Gosselin, C, Verges-Belmin, V, Royer, A \& Martinet, G 2008. Natural cement and monumental restoration. Materials and Structures, 42: 749-763.

Groot, C J W P, Ashall, G J, Hughes, J J \& Bartos, P J M (2004. Characterisation of old mortars with respect to their repair. In: Groot C, Ashall G \& Hughes J J (Eds). RILEM TC 167-COM: State-of-the-Art Report. doi:10.1617/2912143675.007.

Gulzar, S, Chaudhry, M N, Burg J P \& Saeed S A 2013. Characteristics of ancient mortars and plasters from the archaeological site of Akbari-Serai (Pakistan). Journal of Chemistry, 25(15): 8484-8488.

Hauková, P, Frankeová, D \& Sližková, Z 2013. Characterisation of historic mortars for conservation diagnosis. Proceedings, 3rd Historic Mortars Conference, 11-14 September 2013, Glasgow, Scotland, pp 109-117.

Historic England 2018a. Building materials for historic buildings. Available at: https://historicengland.org. uk/advice/technical-advice/buildings/buildingmaterials-for-historic-buildings (accessed in May 2018).

Historic England 2018b. Principles of repair for historic buildings. Available at: https://historicengland.org. uk (accessed in August 2018).

Holmes, S \& Wingate, M 1997. Building with Lime. London: Intermediate Technology Publications.

Hormes, J, Diekamp, A, Klysubund, W, Bovenkamp, G L \& Börste, N 2016. The characterization of historic mortars: A comparison between powder diffraction and synchrotron radiation-based X-ray absorption and X-ray fluorescence spectroscopy. Microchemical Journal, 125: 190-195.

Isebaert, A, Van Parys, L \& Cnudde, V 2014. Composition and compatibility requirements of mineral repair mortars for stone - A review. Construction and Building Materials, 59: 39-50.

Jedrzejewska, H 1960. Old mortars in Poland: A new method of investigation. Studies in Conservation, 5: 132-138.

Labiadh, M R, Ouezdou, M B, Hajjem, B T \& Mensi, R 2009. Characterization of waterproof-covering mortars on the Ottoman monuments of "Ghar El Melh" (Tunisia). Construction and Building Materials, 23: 423-433. 
Lanas, J \& Alvarez, J I 2003. Masonry repair limebased mortars: Factors affecting the mechanical behaviour. Cement and Concrete Research, 33: 1867-1876.

Lawrence, S J, Samarasinghe, W \& Guirguis, S 2004. Mortar durability. Development and standardization of test methods. Proceedings, 13th International Brick and Block Masonry Conference, 4-7 July 2004, Amsterdam, The Netherlands.

Lopez-Arce, P, Tagnit-Hammou, M, Menendez, B et al. 2016. Physico-chemical stone-mortar compatibility of commercial stone-repair mortars of historic buildings from Paris. Construction and Building Materials, 124: 424-441.

Lourenço, P B 2006. Recommendations and advances in research and practice. Construction and Building Materials, 20(4): 239-251.

Marini, A, Cominelli, S, Zanotti, C \& Giuriani, E 2018. Improved natural hydraulic lime mortar slab for compatible retrofit of wooden floors in historical buildings. Construction and Building Materials, 158: 801-813.

Martínez, I, Castillo, A, Martínez, E \& Castellote, M 2013. Physico-chemical material characterization of historic unreinforced masonry buildings: The first step for a suitable intervention. Construction and Building Materials, 40: 352-360.

Mata, R L S 2009. Heritage conservation: Applying [the] scientific method in architecture. The Lingayen Capital Building. MUHON: A Journal of Architecture, Landscape Architecture and the Designed Environment, (3): 28-37.

Meli, R, Roberto, M T \& Sánchez-Ramírez, N 2007. Criteria and experiences on structural rehabilitation of stone masonry buildings in Mexico City. International Journal of Architectural Heritage, 1(1): 3-28.

Middendorf, B, Hughes, H, Callebaut, K, Baronio, G \& Papayianni, I 2005a. Investigation methods for the characterisation of historic mortars. Part 1: Mineralogical characterisation. Materials and Structures, 38: 761-769.

Middendorf, B, Hughes, H, Callebaut, K, Baronio, G \& Papayianni, I 2005b. Investigation methods for the characterisation of historic mortars. Part 2: Chemical characterisation. Materials and Structures, 38: 771-780.

Morricone, A, Macchia, A, Campanella, L et al. 2013. Archeometrical analysis for the characterization of mortars from Ostia Antica Andrea. Procedia Chemistry, 8: 231-238.

Mwasinga, B 2018. Interview with the Built Environment Manager of SAHRA (South African Heritage Resources Agency) on 26 July 2018, Cape Town, South Africa.

Ontiveros-Ortega, E, Rodríguez-Gutiérrez, O \& Navarro, A D 2016. Mineralogical and physicalchemical characterisation of Roman mortars used for monumental substructures on the Hill of San Antonio, in the Roman city of Italica (prov. Baetica, Santiponce, Seville, Spain). Journal of Archaeological Science, 7: 205-223.

Özkaya, Ö A \& Böke, A 2009. Properties of Roman bricks and mortars used in Serapis temple in the city of Pergamon. Material Characterization, 60: 995-1000.

Papayianni, I \& Pachta, V 2014. Experimental study on the performance of lime-based grouts used in consolidating historic masonries. Materials and Structures, 48(7): 2111-2121.

Papayianni, I \& Pachta, V 2017. Earth block houses of historic centres. A sustainable upgrading with compatible repair materials. Procedia Environmental Sciences, 38: 274-282.

Penelis, G G 1996. Techniques and materials for structural restoration. Proceedings, 11th World Conference on Earthquake Engineering, 23-28 June 1996, Acapulco, Mexico, Paper No. 2089. Penelis, G G, Karaveziroglou, M \& Papayianni, J 1989. Materials used in the restoration of historical buildings and monuments. Proceedings, 1st International Symposium on Concrete and Masonry Structures.

Podiapolski, S, Bessonov, G, Beliaev, L \& Postnikova, T 1988. Restoration of monuments. Principles of repair for historic buildings. Moscow: Stroiisdat.

Republic of South Africa 1999. National Heritage Resources Act 25 of 1999, Section 35(4).
Rodriguez-Navarro, C, Hansen, E \& Ginell, W S 1998. Calcium hydroxide crystal evolution upon aging of lime putty. Journal of the American Ceramics Society, 81(11): 3032-3034.

SAHRA (South African Heritage Resources Agency) 2018a. Conditional assessment of buildings on Robben Island. Outline description of material testing required. Available at: https://sahris.sahra.org.za/sites/default/ files/additionaldocs (accessed in March 2019).

SAHRA 2018b. Owl House Museum site report. June 2018. Available at: http://www.sahra.org.za

SAHRA 2018c. Declared Heritage Sites in South Africa. Available at: https://www.sahra.org.za/sahris/ declaredsites (accessed in August 2018).

Salvadori, M 1982. Why Buildings Stand Up: The Strength of Architecture. New York: McGraw-Hill.

Sandbhor, S \& Botre, R 2013. A systematic approach towards restoration of heritage buildings: A case study. International Journal of Research in Engineering and Technology, 2: 229-238.

Schueremans, L, Cizer, Ö, Janssens, E, Serré, G \& Van Balen, K 2011. Characterization of repair mortars for the assessment of their compatibility in restoration projects: Research and practice. Construction and Building Materials, 25: 4338-4350.

Singh, M, Waghmare, S \& Kumar, V 2014. Characterization of lime plasters used in 16th century Mughal monument. Journal of Archaeological Science, 42: 430-434.

Van Balen, K, Ercan, S \& Patricio, C 1999. Compatibility and retreatability versus reversibility: A case study at the Late Hellenistic Nymphaeum of Sagalassos (Turkey). In Sickels-Taves, L B (Ed). The use of and need for preservation standards in architectural conservation. ASTM STP 1335, West Conshohocken, PA, pp 105-118.

World Heritage Sites in South Africa 2018. Available at: http://www.mediaclubsouthafrica.com/culture (accessed in September 2018).

World Travel and Tourism Council 2018. Travel \& Tourism, Economic Impact, South Africa. Available at: https://www.wttc.org (accessed in August 2018). 